\title{
A degeneração dos espaços públicos e a supervalorização narcísica como facetas do mal-estar no trabalho
}

\author{
Marcos Paulo Shiozaki ${ }^{\mathrm{I}}$, Francisco Hashimoto ${ }^{\mathrm{II}}$ \\ ${ }^{\mathrm{I}}$ Universidade Estadual de Maringá (Maringá, PR, Brasil)

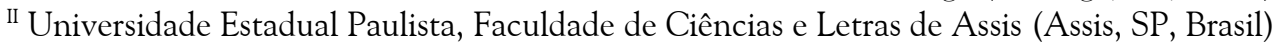

Em alguns espaços, o modelo de trabalho está se caracterizando de maneira diferente nos tempos atuais quando comparado com aquela forma taylorista que ainda predomina em muitas organizações, com a clássica figura centralizada no chefe e nas metas. Justamente devido a essas mudanças, esse novo modelo apresenta uma boa notoriedade por se centrar no indivíduo e por uma proposta de uma suposta liberdade dentro de ambientes laborais, onde não existem metas e a figura do chefe é dissolvida. É possível perceber que essa supervalorização no indivíduo cria espaços cada vez mais particulares e individualistas, na mesma medida em que existe uma diminuição do investimento de lugares que prezam a coletividade. Diante disso, o objetivo deste escrito é analisar como a degeneração dos espaços públicos e a supervalorização narcísica se apresentam como fatores de mal-estar no trabalho. Para realizar este estudo, foram utilizadas algumas obras psicanalíticas freudianas e balintianas, além do aporte dos autores da Psicossociologia. Assim, defende-se aqui que o declínio dos espaços públicos e a exacerbação narcísica, tão relacionada ao trabalho, levam cada vez mais dificuldades aos indivíduos em encontrarem espaços efetivos de satisfação pulsional.

Palavras-chave: Mal-estar no trabalho, Espaço público, Narcisismo.

The degeneration of public spaces and narcissistic overvaluation as facets of malaise at work

In some spaces, the work model is being characterized differently in the present times when compared to that Taylorist way that still predominates in many organizations, with the classic figure centered on the boss and the goals. Precisely because of these changes, this new model has a good reputation for focusing on the individual and a proposal for supposed freedom in working environments where there are no goals and the figure of the boss is dissolved. It is possible to perceive that this overvaluation in the individual creates increasingly particular and individualistic spaces, in the same way that there is a decrease in the investment of places that value the collectivity. Therefore, the purpose of this paper is to analyze how the degeneration of public spaces and the narcissistic overvaluation present themselves as factors of malaise at work. In order to carry out this study, some Freudian and Balintian psychoanalytic works were used, in addition to the contribution of the authors of Psicossociology. Thus, it is argued here that the decline of public spaces and narcissistic exacerbation, so labor-related, are increasingly difficult for individuals to find effective spaces for drive satisfaction.

Keywords: Malaise at work, Public space, Narcissism.

\section{Introdução}

$\mathrm{D}$ e acordo com Habermas (1984), a diferenciação entre o público e o privado teve origem na Grécia e se consolidou juridicamente no Estado moderno. O espaço público, então, envolve e depende da condição dessas duas categorias, já que ela se configura como um importante lugar em que existe um potencial dialógico dessas duas esferas.

Diante disso, é de se esperar que no espaço público desenvolva um potencial de crescimento humano a partir da diversidade das discussões, da cultura e dos atos das pessoas que esse local exibe e proporciona. As trocas simbólicas são essenciais e caracterizam este 
espaço em que são possíveis debates e intervenções sobre os mais diferentes assuntos, como família, sociedade, religião, trabalho etc.

É justamente esse último assunto, o trabalho, que iremos explorar neste artigo, cujo objetivo é analisar como a degeneração dos espaços públicos e a supervalorização narcísica se apresentam como facetas do mal-estar no trabalho.

\section{O mal-estar no trabalho e a utilização dos espaços públicos}

A discussão realizada por Freud (1930/2010) em relação à civilização, segundo a qual viver sob a égide da cultura seria renunciar aos nossos aspectos narcísicos, é instigante. Isso porque, se pensarmos que a renúncia a nossos desejos nos levaria a um sofrimento e, ao mesmo tempo, nos proporcionaria a entrada na cultura, logo pareceria não haver possibilidades de se atingir uma forma de obtenção de prazer nos espaços públicos, já que esses são frutos dessa mesma cultura/civilização.

Uma das características mais marcantes de nossa civilização seria o trabalho. Aliás, é impossível pensarmos na cultura sem a presença do trabalho. Quando utilizamos a lógica freudiana, ainda, apresentada nesse texto (Freud, 1930/2010), temos a afirmação de que o trabalho seria a principal condução para se firmar alguém em uma realidade (que permite a nossa condição de membros de uma sociedade) e, consequentemente, a um terrível sofrimento.

Mas, qual tipo de sofrimento seria este relacionado por Freud? Em qual tipo de trabalho ele estaria pensando?

Ao analisar o contexto de expansão industrial na Europa daquele período, conjecturamos que o modelo de trabalho daquele tempo, provavelmente, seria mais próximo do funcionamento taylorista-fordista, fragmentado, que, consequentemente, levaria a uma alienação no trabalho. Diante desse cenário, fica difícil destinar ao trabalho um local de vazão e satisfação libidinal, sendo muito mais fácil relacioná-lo a um espaço de acúmulos de tensão e de múltiplas insatisfações.

Nesse mesmo tempo mencionado, havia uma valorização do espaço público, em que algumas praças e terrenos vazios eram ocupados por parques, circos, feiras, eventos itinerantes etc. Defendemos aqui a existência de uma relação direta desses sítios com aquele modelo de trabalho taylorista-fordista. O parque de diversões, por exemplo, ganhou destaque na obra de Balint (1959/1987) como um local presente na maioria dos lugares do mundo e que representaria uma quebra na rotina e no trabalho, levando as pessoas a se divertirem. Além disso, era comum nesse local ter comida, prazeres agressivos (como atirar em coisas), prazeres ligados a sensações como tontura, falta de estabilidade (como nos carrosséis, rodas gigantes), mostras que remeteriam ao primitivo (mulher gorila, por exemplo), jogos, adivinhações e jogos de azar.

Além disso, as comidas eram, geralmente, baratas e doces. Os jogos agressivos envolviam atirar, destruir ou medir forças. De acordo com Balint (1959/1987), tudo isso estaria ligado ao processo regressivo, ao se pensar na oralidade e na questão instintiva de destruição. Sendo assim, podemos classificar o parque de diversões como um dos meios em que a civilização acabou aceitando alguns prazeres, possibilitando um certo "escape" frente às imposições culturais e sociais advindas do social e do trabalho.

Esses parques públicos, então, representariam espaços onde o sujeito poderia ser incitado, estimulado e recompensado por ser agressivo. Quanto menos ansiedade e inibição ele sentisse, mais agressivo ou destrutivo ele poderia ser (Balint citou exemplos, como acertar no alvo, esmagar algo etc.). Isso levaria a uma questão de uma relação objetal diferenciada, pois seguiria um caminho distinto do que foi estipulado culturalmente. 
O exemplo do parque de diversões parece deixar clara a necessidade do espaço público frente às imposições sociais colocadas. Entretanto, a mesma lógica se aplicaria a outros espaços, como os parques, as praças, as feiras etc.? Continuamos a acreditar que sim, pois também há formas de vazões nesses lugares frente ao sofrimento do trabalho, expressadas na utilização desses locais para lamentações e discussões coletivas sobre as condições a que as pessoas devem obedecer para sobreviver, além de outras atividades que podem auxiliar a espairecer os problemas da realidade.

Temos, portanto, que as restrições impostas através de leis, instituições e tradições acabam sufocando e impossibilitando o homem a atingir o princípio do prazer, ou seja, satisfazer seus impulsos. Diante disso, como pensar em um homem livre, autônomo e feliz, se o seu trabalho o prende e o limita a realizar aquela atividade específica e fragmentada?

\section{O trabalho e o sujeito na atualidade}

As indústrias se apoiaram bastante nesse ideal taylorista-fordista e, até hoje, percebemos que fatores como a questão da produtividade, da fragmentação e do controle do tempo continuam presentes em nosso atual ambiente de trabalho.

Entretanto, vale apontar que, em diversas localidades e com a expansão do neoliberalismo, os modelos de gestão foram se modificando ao longo do tempo; a presença da Administração de Recursos Humanos causou um importante impacto e alterou diversas práticas desempenhadas nas atividades laborais, por mais que ela ainda continuasse a visar às questões que envolviam maior produtividade com custo reduzido.

Pagès, Bonetti, Gaulejac e Descendre (1993) acenam que essas mudanças encaminharam para um tipo de empresa denominada hipermoderna, que tem as multinacionais como um dos principais modelos organizacionais. Lá, é possível observar executivos que aceitam a ideologia do lucro e da expansão mesmo quando há um prejuízo significativo da saúde e uma ascensão acentuada do sofrimento.

Pagès et al. (1993) apontam que a lógica capitalista é "fragmentada, abstrata, desterritorializada" (p. 13) e essas características são extremamente danosas, pois o trabalho perde a sua integralidade, ou seja, perde o seu sentido. Além disso, é preciso considerar que não existe uma separação do trabalho em relação à nossa vida privada ou à nossa vida coletiva, significando que a alienação no trabalho denota também uma alienação da vida privada e coletiva.

Dessa maneira, todo o sentido que poderíamos estabelecer nas diversas instâncias de nossa vida acaba ficando reduzido ao econômico, levando a uma mudança em nosso modo de ver e produzir no mundo. Assim, acreditamos que fragmentar o sujeito em aspectos do trabalho, da vida privada e da vida coletiva seja algo complexo, justamente porque elas são interdependentes. Então, analisar essas mudanças em quaisquer das instâncias acaba, automaticamente, refletindo no sujeito como um todo.

A empresa onde o sujeito se insere hoje busca metas impossíveis, em que não basta apenas ser rentável, mas ser melhor que as outras. Gaulejac (2007) destaca ainda que não “...se trata mais de ser produtivo, mas de eliminar os concorrentes (...) transforma-se a sociedade em terreno de jogo, banaliza-se a busca megalomaníaca de seus dirigentes e naturaliza-se a ideia de guerra econômica" (p. 169). Diante dessa afirmação, nos questionamos como o homem aceitou tão passivamente a essa condição.

É fato que o modelo de trabalho taylorista daria uma possibilidade de um certo distanciamento entre a vida pessoal e a vida laboral, apesar de toda alienação envolvida. Mas o modelo das empresas hipermodernas parece engolfar o trabalhador a ponto de ele não mais se reconhecer sem os ideais empresariais. 


\section{Aspectos psicanalíticos envolvendo os modos de produção}

Quando analisamos o pensamento freudiano, a questão edípica aparece de maneira central para o entendimento dessa teoria. Defendemos que a ênfase dada ao Édipo, por parte de Freud (1913/2012), se justifica pelo contexto em que o vienense viveu, corroborando também o pressuposto de uma existência da integração da vida profissional, pessoal e coletiva. Ou seja, o modelo edípico parecia se encaixar perfeitamente nas necessidades do raciocínio de Freud, ao se pensar naquele período em que o trabalho era marcado pelo taylorismo-fordismo.

Balint (1968/1993) explicou que, na área edípica, o bebê estaria em uma relação quase que exclusiva com a figura materna e sofreria com a entrada de um terceiro muito forte, representado pela figura paterna. A consequência da chegada desse terceiro levaria a algumas frustrações ao bebê, que desejaria se realizar amorosamente com a figura materna, por mais que essa frustração o forçaria a uma entrada na cultura. Isso significa que o bebê deveria renunciar ao amor materno, mas em troca ganharia o seu ingresso na cultura, com a aquisição da linguagem, dos conflitos etc.

Quando pensamos naquela organização taylorista-fordista, parece que enxergamos exatamente essa condição: um chefe com uma presença forte que impede o funcionário de realizar seus desejos na empresa. Diante disso, o trabalhador pode entrar em conflito e, inclusive, debater, discutir, agir e reagir sobre a sua condição de trabalho nos diversos espaços públicos.

Por outro lado, existe uma relação muito mais regredida, pré-edípica, em que não existe a entrada desse terceiro. Freud (1914/2010) destacou que esse desenvolvimento, que se caracteriza pela bipessoalidade, seria marcada pelo narcisismo. O termo narcisismo, de acordo com Laplanche e Pontalis (2004), se refere a uma retenção libidinal no eu. Hornstein (2009) apontou que os pacientes que se encontram nessa dimensão narcísica são muito sensíveis em relação à intrusão em seus espaços, além de eles temerem demasiadamente uma separação, justamente por uma espécie de nostalgia de fusão (relacionado à bipessoalidade). $\mathrm{O}$ autor ainda relatou que, em uma perturbação narcísica, está presente uma angústia que parece elevar o risco de fragmentação. O que conseguimos observar nos casos de narcisismo, de acordo com Balint (1968/1993), seria a presença de um objeto externo, poderosíssimo, o qual o bebê admira e com o qual se relaciona e se identifica.

Pagès et al. (1993) demonstrou que o sujeito, frente a uma empresa hipermoderna, se sente inferior e cheio de angústias, devido ao poder que esse local emana e que, ainda, pode gratificá-lo. Com isso, o indivíduo se identifica e se projeta nessa empresa poderosa, introjetando-a e se sentindo mais do que pertencente àquela organização, como se ele próprio fosse e tivesse os mesmos ideais dessa organização. Como consequência disso, temos uma dissolução da capacidade crítica desse trabalhador de tudo que for contra essa empresa, cultuando-a, e fazendo também com que ele se dedique integralmentea a ponto de se chegar a um isolamento desse ser: "...é o sucesso individual no trabalho e na carreira, e é o salário como sinal de mérito individual” (Pagés et al., 1993, p. 164).

Corroborando essa ideia, Enriquez (1997) aponta que a organização possui um complexo sistema cultural, simbólico e imaginário. Isso significa que, no trabalho, existem os valores da empresa e as normas a serem seguidas - que ditam as narrativas dos trabalhadores e, por muitas vezes, acabam por substituírem os ideais dos indivíduos pelos ideais da organização.

As formas de sedução dessas empresas exemplificam muito bem esse modo de dominação. Temos hoje empresas que concedem inúmeros benefícios (celulares, carros, computadores, viagens, premiações etc.) e, ainda, não estabelecem explicitamente as metas de trabalho, tendo o chefe (que antigamente era associado a uma pessoa autoritária) como um grande parceiro. 
Por outro lado, temos um trabalhador que não quer perder essas diversas vantagens e se sente muito integrado a essa organização. Como consequência, temos aquele funcionário (ou colaborador) que não se desliga nunca de seu trabalho como se sua vida fosse somente o seu trabalho, realmente.

Gaulejac (2007) critica esse ponto e demonstra que esse parece ser o novo ideal social: além de reduzir e justificar tudo na vida às facetas econômicas, ainda querem que qualquer pessoa seja aquele empreendedor para agir em um mundo produtivista. "O manager emerge como figura do homem ideal que empreende, capaz de assumir riscos, decidir, resolver problemas complexos, suportar o estresse, desenvolver sua inteligência cognitiva e também emocional, pôr todas as suas qualidades a serviço da rentabilidade" (Gaulejac, 2007, pp. 179. 180).

Essa bipessoalidade que leva ao sujeito uma condição de uma relação doentia com a organização faz com que o indivíduo não meça esforços para que a empresa cresça cada vez mais e liquide os seus concorrentes. A constante busca por inovação, criatividade e desempenho leva o trabalhador a uma obsessão doentia e a um isolamento cada vez maior, se sentindo cada vez mais realizado pelas suas exclusivas e merecidas conquistas quando consegue obter algum sucesso.

Esse fator isola cada vez mais o sujeito num individualismo, limitando-o a constantes e intocáveis satisfações narcísicas, tentando alcançar um ideal impossível e que apenas cresce e fica mais exigente. Os fatores públicos se tornam inutilizados e desvalorizados, pois, no narcisismo, o que importa seria exclusivamente o privado, ou seja, "o que eu fiz", o "que eu faço" e o "que eu penso", como um bebê, que, por certo tempo, é dono de uma incrível onipotência, se vê poderoso e produtor de tudo o que ocorre em sua volta, tal como ele idealiza em sua figura materna.

\section{O público privado}

Diante dessa ênfase nos aspectos individuais, narcísicos, percebemos que o lugar público se tornou muito arriscado. Existem perigos em praças e parques e esses locais estão cada vez mais inutilizados e associados a algo negativo. Frente a essa degradação, é comum observamos uma impassibilidade e uma desistência de qualquer ato que denotaria uma revitalização.

Existiria um lugar que possibilitaria um espaço dialógico entre o público e o privado, que poderia servir como um "escape" das tensões acumuladas ao longo do trabalho? As redes sociais serviriam para isso?

Acreditamos que as redes sociais são locais virtualizados que potencializariam essas possibilidades de articulações e de debates. Em contrapartida, percebemos que existe um movimento de individuação nesse espaço e que o público apenas "serve de público" para admirar esse exibicionista (Sibilia, 2008). Isso significa que esses espaços representam somente uma vitrine para tentar satisfazer o intrépido e insaciável narcisismo.

Portanto, o local em que eu tento dar vazão aos meus impulsos reprimidos nunca será satisfeito, levando, então, a um acentuado movimento de ascensão do individualismo, chegando a níveis em que não é mais possível aceitar e, muito menos, tolerar aquele outro que não concorda com "o importante e o insubstituível" eu narcísico.

Tudo isso representa um sintoma de uma sociedade, de um trabalho, de um público e de um privado doente. 


\section{Considerações finais}

Por fim, qual deveria ser o grande objetivo do trabalho? Com certeza, não seria criar mais dependência de atividades fragmentadas ou reduzir todas as relações a aspectos econômicos. Defendemos aqui que o labor deveria levar o sujeito a um movimento de maior autonomia.

Barus-Michel (2004) concorda com isso e aponta que os indivíduos deveriam se comprometer socialmente frente a uma causa e, nesse momento, eles deixariam de ser sujeitosindivíduos para serem sujeitos-sociais. Defendemos aqui que o espaço público, que permite a discussão e a vazão do que está reprimido, poderia ser um importante sítio que promoveria essa maior interlocução dessa transformação.

Dessa maneira, o processo de mudança seria um ótimo indicativo e sinônimo de saúde mental, pois romperia com as questões estereotipadas e instituídas pelo mundo do trabalho e, consequentemente, do mundo privado, do coletivo e do público. Tudo isso colaboraria para um sujeito mais autônomo, capaz de atingir um ideal de trabalho defendido por Enriquez (2014), de uma possibilidade de um labor sublimatório. Acreditamos que tudo isso teria que ocorrer em um nível coletivo, permitindo, então, a ascensão do sujeito social, mais consciente e menos alienado em relação ao seu trabalho, pois, para se atingir aquele ideal de Enriquez (2014), o trabalho deve, simplesmente, fazer sentido.

\section{Referências}

Balint, M. (1987). Thrills and regressions. Londres: Maresfield Library. (Originalmente publicado em 1959)

Balint, M. (1993). A falha básica: aspectos terapêuticos da regressão (F. F. Settineri, trad.). Porto Alegre: Artes Médicas. (Originalmente publicado em 1968)

Barus-Michel, J. (2004). O sujeito social (Trad. E. Galery, V. M. Machado). Belo Horizonte: Editora PUC Minas.

Enriquez, E. (1997). A organização em análise (Trad. F. Rocha Filho). Petrópolis, RJ: Vozes.

Enriquez, E. (2014). Jogos de poder na empresa: sobre os processos de poder e estrutura organizacional (Trad. E. D. Galery et al.). São Paulo: Zagodoni.

Freud, S. (2012). Totem e tabu. In S. Freud. Totem e tabu, Contribuição à história do movimento psicanalítico e outros textos (Trad. P. C. L. Souza). São Paulo: Companhia das Letras. (Originalmente publicado em 1913)

Freud, S. (2010). Introdução ao narcisismo. In S. Freud. Introdução ao narcisismo, Ensaios de metapsicologia e outros textos (Trad. P. C. L. Souza). São Paulo: Companhia das Letras. (Originalmente publicado em 1914)

Freud, S. (2010). O mal-estar na civilização. In S. Freud. O mal-estar na civilização, novas conferências introdutórias e outros textos (Trad. P. C. L. Souza). São Paulo: Companhia das Letras. (Originalmente publicado em 1930)

Gaulejac, V. (2007). Gestão como doença social: ideologia, poder gerencialista e fragmentação social. Aparecida, SP: Ideias e Letras.

Habermas, J. (1984). Mudança estrutural da esfera pública: investigações a uma categoria da sociedade burguesa (F. R. Kohte, trad.). Rio de Janeiro: Tempo Brasileiro.

Hornstein, L. (2009). Narcisismo: autoestima, identidade, alteridade. (Trad. R. Faria). São Paulo: Via Lettera, Centro de Estudos Psicanalíticos.

Laplanche, J. \& Pontalis, J.-B. (2004). Vocabulário de psicanálise. (Trad. P. Tamen). São Paulo: Martins Fontes.

Pagès, M., Bonetti, M., Gaulejac, V., \& Descendre, D. (1993). O poder das organizações (Trad. M. C. P. Tavares, S. Favatti). São Paulo: Atlas.

Sibilia, P. (2008). O show do eu: a intimidade como espetáculo. Rio de Janeiro: Nova Fronteira. 


\section{Endereço para correspondência}

marcos.shiozaki@gmail.com, franciscohashimoto@gmail.com

Recebido em: 16/01/2017

Revisado em: 03/07/2017

Aprovado em: 10/07/2017 